Iwan Setiawan $^{1)}$, Khana Wijaya ${ }^{2)}$,Yeni Yuliana ${ }^{3)}$

Informatika : Fakultas Sains dan Teknologi

Universitas Labuhanbatu

Vol. 8 No.3 /September/2020

2615-1855 (E-ISSN)

2303-2863 (P-ISSN)

\title{
APLIKASI MEDIA PEMBELAJARAN PENGENALAN HURUF ALFABET MENGGUNAKAN ADOBE FLASH CS3.
}

\author{
Iwan Setiawan $^{1)}$ \\ Dosen Program Studi Sistem Informasi, STMIK Prabumulih \\ e-mail: iwanhen2@gmail.com \\ Khana Wijaya ${ }^{2)}$ \\ Dosen Program Studi Sistem Informasi, STMIK Prabumulih \\ e-mail: khanawijaya90@gmail.com \\ Yeni Yuliana ${ }^{3)}$ \\ Dosen Program Studi Komputerisasi Akuntansi, STMIK Prabumulih \\ e-mail: yeni.84@yahoo.com
}

\begin{abstract}
ABSTRAK
Taman kanak-kanak Kemala Bhayangkari 11 Prabumulih merupakan salah satu Taman kanak-kanak yang berada dikota Prabumulih yang menggunakan metode belajar-mengajar masih menggunakan teks dan gambar serta tatap muka dengan guru, karena belum adanya aplikasi multimedia. Salah satu faktor yang menghambat, datang dari anak-anak itu sendiri yang terlibat dalam proses belajar mengajar. Kemampuan anak-anak dalam memahami suatu pelajaran tidak lah sama, karena rendahnya minat sebagian anak-anak dalam menjalani aktifitas belajar, sehingga timbul rasa bosan, sulit mengerti pelajaran serta tidak memiliki ketertarikan dalam belajar, karena anak-anak tersebut lebih senang belajar sambil bermain. Berdasarkan hasil penelitian tersebut penulis mencoba merancang suatu Aplikasi media pembelajaran untuk memudahkan anak-anak dalam mengenal huruf alphabet dengan menggunakan Adobe Flash CS3 serta dibantu dengan aplikasi PhotoShop CS3. Dengan adanya media pembelajaran ini, diharapkandapat meningkatkan keaktifan anak-anak Taman kanak-kanak Kemala Bhayangkari 11 Prabumulih serta kualitas pembelajaran serta mutu pendidikan pada Taman kanak-kanak kemala Bhayangkari 11 Prabumulih itu sendiri dan dapat meningkatkan kualitas pembelajaran dan mutu pendidikan pada Taman kanak-kanak Kemala Bhayangkari 11 Prabumulih.
\end{abstract}

\section{Kata kunci: Media Pembelajaran, Adobe Flash CS3, PhotoShop CS3, Huruf Alfabet}

\section{ABSTRACT}

Kindergarten Kemala Bhayangkari 11 Prabumulih is a kindergarten in the city of Prabumulih that uses teaching and learning methods still using text and pictures and face to face with the teacher, because there is no multimedia application. One of the inhibiting factors came from the children themselves who were involved in the teaching and learning process. The ability of children to understand a lesson is not the same, because of the low interest of some children in undergoing learning activities, resulting in boredom, difficulty understanding the lesson and not having an interest in learning, because these children prefer to learn while playing. Based on these results the author 
tries to design a learning media application to facilitate children in recognizing the alphabet letters by using Adobe Flash CS3 and assisted with PhotoShop CS3 applications. With this learning media, it is expected to be able to increase the activities of the children of the Kindergarten Kemala Bhayangkari 11 Kindergarten as well as the quality of learning and the quality of education in the Kindergarten Kemala Bhayangkari 11 Prabumulih itself and can improve the quality of learning and the quality of education in Kindergarten Kemala Bhayangkari 11 Prabumulih.

\section{Keywords: Learning Media, Adobe Flash CS3, PhotoShop CS3, Alphabet Letters}

\section{PENDAHULUAN}

Perkembangan ilmu pengetahuan dan teknologi pada saat ini sangat berpengaruh pada semua bidang kehidupan. Khususnya untuk media pembelajaran sendiri menjadi bagian yang sangat penting dalam proses belajar mengajar. Oleh karena itu, perlu dicari suatu media pembelajaran yang baik bagi anak-anak, sehingga lebih menarik perhatian anak-anak agar merasa senang saat belajar dibandingkan dengan hanya menggunakan buku. Selain itu, pembelajaran dengan menggunakan teknologi informasi melalui media elektronik berbasis multimedia dapat membantu menumbuhkan minat belajar secara mandiri dan mampu mengembangkan kreatifitas dan pemahaman anak didik dalam belajar.

Dengan adanya teknologi komputerisasi khususnya dengan menggunakan Aplikasi Macromedia flash atau Adobe flash.Macromedia flash adalah sebuah program software yang berfungsi untuk membuat animasi yang sangat handal dibandingkan dengan program lain.

Untuk menambah daya ingat siswa dalam pemahaman belajar maka Macromedia flash sangatlah berperan penting sebagai aplikasi media pembelajaran untuk siswa sebagai daya tarik siswa agar tidak jenuh dengan proses belajar yang sehari-harinya hanya menggunakan buku dan papan tulis.
Berdasarkan hasil observasi penulis pada TK. Kemala Bhayangkari II Cabang Prabumulih, khususnya yang mengajar kelas nol (o) dalam proses pembelajaran yang masih manual. Berikut ini dapat di lihat program kurikulum pengajaran di TK. Kemala Bhayangkari 11 prabumulih tahun 2020, berdasarkan tabel dibawah ini:

Tabel 1 Program Kurikulum pada TK. Kemala Bhayangkari 11 Prabumulih

\begin{tabular}{|c|c|c|c|}
\hline \multirow[t]{2}{*}{ No. } & \multirow[b]{2}{*}{$\begin{array}{c}\text { BidangPengembangan } \backslash \\
\text { Program }\end{array}$} & \multicolumn{2}{|c|}{ Tingkat } \\
\hline & & $\mathbf{A}$ & B \\
\hline 1. & $\begin{array}{c}\text { Nilai-Nilai Agama dan } \\
\text { Moral }\end{array}$ & 30 & 30 \\
\hline 2. & Karakter Formal & 30 & 30 \\
\hline 3. & Fisik & 30 & 30 \\
\hline 4. & Kognitif & 30 & 30 \\
\hline 5. & Bahasa & 30 & 30 \\
\hline 6. & SosialEmosional & 30 & 30 \\
\hline
\end{tabular}

Dari tabel 1 diatas dapat dilihat program kurikulum khususnya bahasa dari TK. Kemala Bhayangkari 11 dan tingkat penilaiannya, proses belajar mengajar pengenalan huruf yang masih menggunakan media papan tulis dan buku sehingga penulis ingin membuat suatu aplikasi media pembelajaran agar dapat memberikan kemudahan bagi pengajar dalam menjelaskan materi yang akan di sampaikan. Maka penulis akan mengambil judul"APLIKASI MEDIA PEMBELAJARAN

PENGENALAN 
HURUF ALFABET MENGGUNAKAN ADOBE FLASH CS3".

\section{Landasan Teori \\ 2.1 PengertianAplikasi}

Menurut Anisyah (2010:30) "aplikasi adalah penerapan penggunaan atau penambahan". Dari pengertian diatas, dapat disimpulkan bahwa aplikasi merupakan software yang berfungsi untuk melakukan berbagai bentuk pekerjaan atau tugas-tugas tertentu seperti penerapan, penggunaan dan penambahan data. Aplikasi sudah digunakan dan terus dikembangkan diberbagai kehidupan manusia, dari pekerjaan yang mudah hingga pekerjaan yang sulit yang tidak mungkin dapat dilakukan oleh manusia dapat dilakukan oleh aplikasi.

Menurut Simarmata (2013:15) "aplikasi adalah suatu paket program yang sudah jadi dan dapat digunakan. Sedang kan arti aplikasi lain adalah program komputer yang dibuat manusia untuk melaksanakan tertentu".

\subsection{Pengertian Media}

Menurut Sadiman (2006:7), “media adalah segala sesuatu yang dapat digunakan untuk menyalurkan pesan dari pengirim kepenerima sehingga dapat merangsang pikiran, perhatian, minat serta perhatian siswa sehingga proses belajar terjadi”.

Menurut Azhar Arsyad (2011:4),"media adalah alat untuk menyampaikan atau mengantarkan pesanpesan pembelajaran”.

\subsection{PengertianPembelajaran}

Menurut Syaiful Sagala (2010:61),"pembelajaran adalah membelajarkan siswa menggunakan asas pendidikan maupun teori belajar yang merupakan penentu utama keberhasilan pendidikan".

Menurut

Trianto (2010:17),"pembelajaran merupakan aspek kegiatan manusia yang kompleks, yang tidak sepenuhnya dapat dijelaskan".

\subsection{Pengertian Huruf Alfabet}

Prihantini (2015:14),"huruf alphabet adalah rentetan huruf dalam bentuk lambing atau gambaran dari bunyi yang menjadi sarana untuk melukiskan bahasa dalam bentuk lambing tulisan".

\section{METODE PENELITIAN}

Berdasarkan jenis penelitian yang digunakan penulis adalah penelitian Deskriptif. Adapun tujuan dari penelitian deskriptif adalah :

1. Menggambarkan mekanisme sebuah proses atau hubungan.

2. Menyajikan informasi dasar.

3. Menjelaskan tahapan-tahapan atau seperangkat tatanan.

Dalam penelitian ini jenis penelitian yang digunakan adalah penelitian rekayasa yaitu penelitian yang menerapkan ilmu pengetahuan menjadi suatu rancangan guna mendapatkan kinerja sesuai dengan persyaratan yang ditentukan.Rancangan tersebut merupakan sintesis unsur-unsur rancangan yang dipadukan dengan metode ilmiah menjadi suatu model yang memenuhi spesifikasi tertentu.Penelitian diarahkan untuk membuktikan bahwa rancangan tersebut memenuhi spesifikasi yang ditentukan. Penelitian berawal dari menentukan spesifikasi rancangan yang memenuhi spesifikasi yng ditentukan, memilih alternatif yang terbaik, dan membuktikan bahwa rancangan yang dipilih dapat memenuhi persyaratan yang ditentukan secara efisiensi, efektif dan 
dengan biaya yang murah.Penelitian perangkat lunak komputer dapat digolongkan dalam penelitian rekayasa.

\section{Desain Penelitian}

Desain Penelitian merupakan suatu kegiatan yang mengandung unsur-unsur yang membantu dalam kegiatan penelitian seperti yang telah ada dalam metode pengumpulan data yaitu datang ke tempat penelitian, melakukan wawancara, dan sebagainya.Menentukan permasalahan yang hendak dipecahkan, mempunyai tujuan penelitian, melakukan kajian ilmiah dan menetapkan aturan metode penelitian yang tepat dan sesuai dengan permasalahannya.

Agar mempunyai desain penelitian yang komprehensif tentang suatu kegiatan penelitian, berikut ini akan ditampilkan secara singkat karakteristik penting dari penelitian yaitu sebagai berikut :

1. Mempunyai tujuan penelitian, tujuan penelitian adalah hal penting dan utama dalam setiap kegiatan penelitian.

2. Mencakup kegiatan pengumpulan data baru yang terjun langsung dan mencari data di lapangan

3. Mencakup kegiatan yang terencana dan sistematis sejak tahap awal atau ditentukan permasalahan penelitian.

\section{HASIL DAN PEMBAHASAN}

Perangkat lunak yang dihasilkan dalam penelitian di implementasikan untuk media pembelajaran pada Taman Kanakkanak Kemala Bhayangkari 11 Prabumulih, setelah aplikasi di analisa dan didesain secara rinci, maka akan menuju tahap implementasi. Tahap implementasi merupakan tahap meletakkan aplikasi sehingga siap untuk dioperasikan.
Media pembelajaran untuk proses belajar mengajar dari cara manual ke sistem komputerisasi dengan menggunakan Adobe Flash CS3. Perangkat lunak yang dihasilkan terdiri dari halaman tampilan utama yang memiliki beberapa button untuk mengakses halaman tampilan selanjutnya pada media pembelajaran pengenalan huruf alfabet. Halaman tampilan itu antara lain yaitu halaman tampilan menu utama yang terdiri dari menu per huruf, semua huruf, huruf \& benda dan latihan, halaman menu per huruf terdiri dari huruf aA-Z, halaman menu semua terdiri dari huruf A$Z$, halaman menu huruf $\&$ benda terdiri dari huruf A-Z dan benda.

\subsection{Implementasi Antar Muka}

Implementasi antar muka dilakukan dengan membuat antar muka padabutton yang ada pada aplikasi ini. Setiap halaman yang dibuat akan dibentuk sebuah animasi yang berenteksi flash.Animasi-animasi tersebut selanjutnya dapat diakses dan akan menjadi penghubung antara pengguna dengan aplikasi. Pada tahap implementasi antar muka ini, lebih melihat pada implementasi antar muka halaman utama yang merupkan sentral penghubung dengan antar muka yang lain.

1. Tampilan Halaman Utama

Pada halaman ini button dan background menjadi dalam satu bagianuntuk masuk ke dalam menu tampilan utama. 


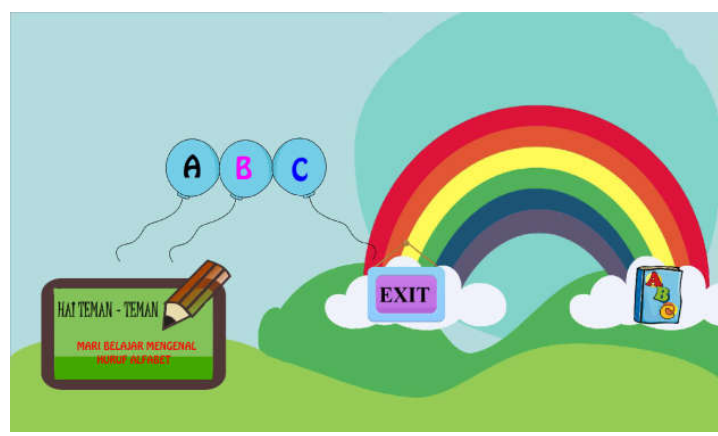

Gambar 1. Halaman Utama Aplikasi

2. Tampilan Halaman Materi

Pembelajaran Pada halaman materi ini merupakan halaman dari bagian materi yang terdapat isi dari materi media pembelajaran

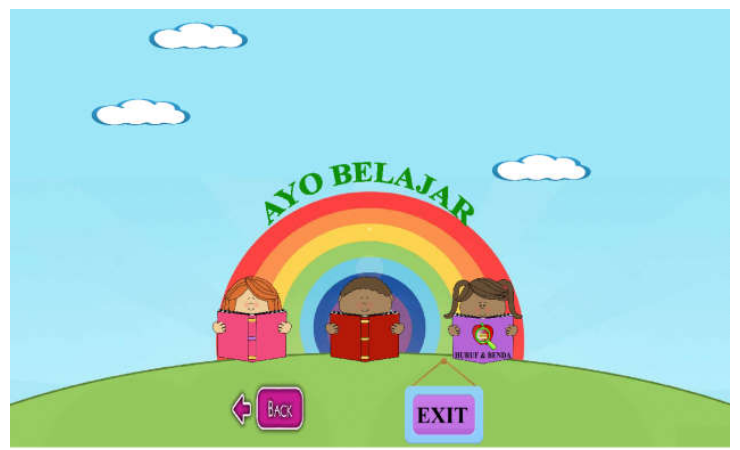

Gambar 2. Halaman materi pembelajaran

3. Tampilan Halaman Materi Pembelajaran Per Huruf

Pada menu halaman materi pembelajaran per huruf merupakan halaman yang berisi huruf alfabet yang berurutan dari huruf A sampai Z.

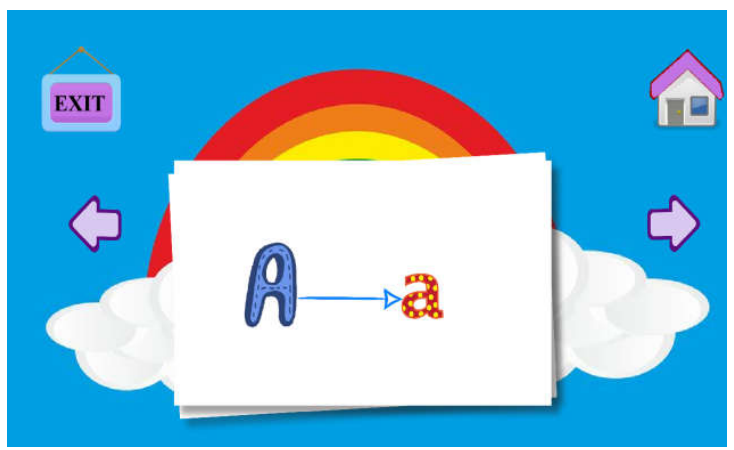

Gambar 3. Halaman Materi Pembelajaran Per Huruf A

\section{KESIMPULAN DAN SARAN}

\subsection{Kesimpulan}

Dari hasil pembahasan penelitian, maka dapat diambil kesimpulan dalam pembuatan penelitian ini adalah :

1. Aplikasi ini menampilkan huruf berdasarkan urutan A-Z.

2. Aplikasi ini menampilkan huruf dan benda dari huruf A-Z.

3. Aplikasi ini dibuat untuk meningkatkan daya tarik anak didik agar lebih senang dalam belajar.

\subsection{Saran}

Aplikasi ini mungkin masih jauh dari kata sempurna dan masih banyak kekurangan, maka dari itu penulis memberikan saran diantarnya :

1. Di harapkan Aplikasi ini bisa di kembangkan lagi menjadi suatu sistem pembelajaran berbasis online.

2. Di harapkan aplikasi ini juga dapat dikembangkan menjadi pengenalan huruf dalam bahasa asing. 
3. Di harapkan Aplikasi ini juga bisa di tingkatkan lagi baik dalam bentuk variasi design dan visualisasi.

4. Di harapkan aplikasi ini juga dapat dikembangkan menjadi pengenalan huruf dan objek lain.

5. Di harapkan Aplikasi ini juga bisa di gunakan anak-anak bukan hanya pada sekolah tapi juga pada lingkungan lain misalnya di rumah dengan menggunakan android.

\section{DAFTAR PUSTAKA}

[1] Anisyah. 2010. "Konsep Aplikasi dan Desain". Jakarta : PT. Gramedia

[2] Arsyad, Azhar. 2011. "Media pembelajaran". Jakarta : PT Grafindo Persada

[3] Diartono,Dwi Agus. 2008. "Media Pembelajaran Desain Grafis Menggunakan Photoshop Berbasis Multimedia”. Unisbank Semarang

[4] Fowler, Martin.2011.Menggunakan UML.Informatika.Bandung

[5] Hakim, Zainal. 2012. "Sejarah Adobe Photoshop". Jakarta : PT. Gramedia Pustaka

[6] Umum .

[7] Prihantini, Ainia. (2015). "Master Bahasa Indonesia”. Yogyakarta: PT. Bentang Pustaka.

[8] Sadiman, Arief, dkk. 2006. "Media Pendidikan Pengertian, Pengembangan, dan Pemanfaatan". Jakarta : Raja Grafindo
[9] Sagala, Syaiful. 2010. “Konsep Dan Makna Pembelajaran”. Bandung : Alfabeta

[10] Script Island. 2008. "Panduan Mudah Membuat Animasi”. Jakarta : Media Kita

[11] Simarmata. (2013). "Analisis dan Desain Aplikasi Multimedia”. Jakarta : PT.Gramedia.

[12] Trianto. 2010. "Mendesain Model Pembelajaran Inovatif-Progresif'. Jakarta : Kencana Carapedia

[13] Whitten dan Bentley.2007.Unified Modeling (UML).Informatika.Jakarta

[14] Wikipedia bahasa Indonesia, ensiklopedia bebas, Adobe Flash

Situs web https://id.wikipedia.org/wiki/Adobe Flash, diakses 23 Mei 2016

[16] Yuswanto. 2003. "Rancang Bangun Sistem pendukung Keputusan Menentukan penerima Beasiswa dengan Menggunakan metode Simpele Additive Weighting (SAW). Skripsi Program Studi Tehnik Informatika". Surabaya : Universitas Pembangunan Nasional "Veteran". 